\section{Cellular Physiology and Biochemistry}

Review

\title{
'Repair' Treg Cells in Tissue Injury
}

\author{
Chaoqi Zhang ${ }^{a, b}{\text { Lifeng Li } i^{a, b, c} \text { Kexin Feng }}^{c}$ Daoyang Fand ${ }^{d}$ Wenhua Xue ${ }^{c}$ Jingli Lu ${ }^{c}$ \\ aBiotherapy Center, The First Affiliated Hospital of Zhengzhou University, Zhengzhou, 'Department of \\ Oncology, The First Affiliated Hospital of Zhengzhou University, Zhengzhou, 'Department of Pharmacy, \\ The First Affiliated Hospital of Zhengzhou University, Zhengzhou dDepartment of Orthopedics, Peking \\ University Third Hospital, Beijing, China
}

\section{Key Words}

Treg cells • Tissue injury • Repair

\begin{abstract}
Studies in mice and humans have elucidated an important role for Tregs in promoting tissue repair and restoring tissue integrity. Emerging evidence has revealed that Tregs promoted wound healing and repair processes at multiple tissue sites, such as the heart, liver, kidney, muscle, lung, bone and central nervous system. The localization of repair Tregs in the lung, muscle and liver exhibited unique phenotypes and functions. Epidermal growth factor receptor, amphiregulin, CD73/CD39 and keratinocyte growth factor are important repair factors that are produced or expressed by repair Tregs; these factors coordinate with parenchymal cells to limit injury and promote repair. In addition, repair Tregs can be modulated by IL-33/ST2, TCR signals and other cytokines in the context of injured microenvironment cues. In this review, we provide an overview of the emerging knowledge about Treg-mediated repair in damaged tissues and organs.

\section{Introduction}

Tissues and organs have remarkable capacities to adapt to injury through tissue repairs. When damage occurs, inflammatory responses are triggered, which subsequently recruit and activate haematopoietic and non-haematopoietic cells that together orchestrate a cellular response to promote tissue repair [1]. Among the immune cells involved in the response to tissue injury, recent findings have expanded our understanding of repair mechanisms by demonstrating new and unexpected roles for some immune cells in repairing damaged tissue according to organ-specific cues [2-5]. Forkhead box P3-expressing (Foxp3 ${ }^{+}$) regulatory $\mathrm{T}$ (Treg) cells are a heterogeneous population that are specializes in antagonizing overexuberant immune responses and restoring immune homeostasis [6]. Recent studies using transgenic mice specifically ablated Tregs have highlighted their nontraditional function in modulating nonimmunological processes through acting on nonimmune targets $[7,8]$. The nontraditional role of Tregs in injured tissues has been accepted as a facet of C. Zhang and L. Li contributed equally to this work. 
Tregs, which has been shown to be of import in the pro-repair and pro-regenerative process [9]. Of note, although functionally important associations between Tregs and tissue repair after injury have been studied for decades, the cellular mechanisms underlying this process have only recently been revealed by studies examining tissue-resident Tregs [10]. Here, we summarize recent findings that converge on Treg-mediated repair in the context of both acute and chronic tissue injury. We focus in detail on the identification of a distinct phenotype of repair Tregs in local settings and discuss Treg-producing or expressing prorepair factors that directly function on nonimmune targets in response to organ-specific cues. Lastly, we highlight factors that promote the development and function of repair Tregs in injured tissues.

\section{Treg-mediated repair at multiple tissues}

Emerging studies have demonstrated that Tregs contribute to the maintenance of tissue homeostasis by promoting wound healing and repair processes at multiple tissue sites (Fig. 1).

In the context of myocardial infarction (MI), Tregs limit tissue injury and promote regeneration. For example, Tregs improved scar tissue formation and survival and protected against adverse ventricular remodelling; furthermore, genetic ablation of Foxp3 ${ }^{+}$Tregs resulted in aggravated cardiac inflammation, a more pronounced left-ventricular dilation and impaired cardiac function $[11,12]$. Therapeutic Treg activation increased expression of tissue inhibitors of matrix metalloproteinases (TIMPs), preventing extracellular collagen matrix degradation in mice [12]. In vitro, Tregs produced TGF- $\beta 1$, IL-13 and IL-10, which synergized to induce M2-like differentiation and subsequently promote osteopontin release from monocytes/macrophages [12]. In addition, Tregs reduced the expression of $\alpha$-smooth muscle actin and attenuated the contraction of fibroblast-populated collagen pads, which suggests that Tregs modulate the cardiac fibroblast phenotype [13].

Similar associations between Tregs and the repair process are also evident in the injured kidney and liver. Tregs were observed to infiltrate in ischaemic-reperfused kidneys, which modulated pro-inflammatory cytokines production by other immune cells [14-17]. IL-10producing Tregs were involved because the adoptive transfer of IL-10-deficient Tregs into Rag-1 knockout mice failed to recover renal function [15]. Tregs were also involved in the liver repair and fibrosis process. In a bile duct ligation rat model, Treg depletion exacerbated hepatic fibrosis and cholestasis, which was related to significant changes in IL-6 and IL10 production [18]. In chronic hepatitis C virus infection, Tregs were enriched in areas of fibrosis [19], and IL-8-producing Treg acted on hepatic stellate cells and functioned as a profibrogenic factor [20]. Mechanistically, Tregs up regulated the expression of TIMP1, MMP2, TGF- $\beta 1, \alpha$-SMA, collagen and CCL2 in primary human hepatic stellate cells (HSC) [20]. Of note, Tregs-induced HSC activation could be blocked by the addition of neutralizing IL-8 antibody [20].

The importance of Tregs in tissue repair was exemplified when a distinct population of resident Tregs was identified in skeletal muscle that contributed to repair and regeneration following acute injury. Muscle-Tregs rapidly accumulated in the injured skeletal muscle of mice and influenced a series of events that accompanied repair: Tregs promoted a pro- to anti-inflammatory shift in myeloid populations, Tregs regulated coinfiltrating conventional $\mathrm{T}$ cell populations and Tregs interacted with satellite cells that were directly responsible for the repair of injured muscle $[21,22]$. Notably, injury-induced accumulation and proliferation of muscle Tregs were reduced in aged mice [23], which was consistent with age-dependent deterioration of muscle function and muscle dystrophic disease [24]. Further evidence to support the importance of Treg in muscle repair stems from research on muscular dystrophy. Depletion of Tregs exacerbated muscle injury and the severity of muscle inflammation in the mouse model of Duchenne muscular dystrophy [25]. However, paradoxical pathogenic roles for Tregs were reported in chronic muscle injury infected with Toxoplasma gondii. 


\section{Cellular Physiology Cell Physiol Biochem 2017;43:2155-2169

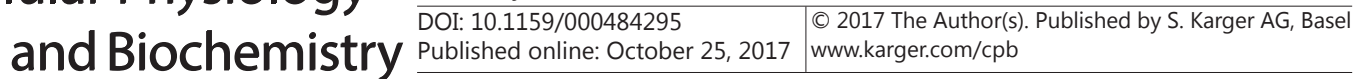

Fig. 1. Tregs promote wound healing and repair processes in multiple injured tissues. The number of Tregs is increased in a variety of injured tissues, and the factors derived from Tregs can mediate repair through immune-related and nonimmune-related mechanisms. The examples of Treg-mediated repair given here include repair of skeletal muscle and neurons; wound healing and mucosa protection; and recovery of liver, heart and kidney function. Abbreviations are as follows: Areg, amphiregulin; Tregs, regulatory $\mathrm{T}$ cells; KGF, keratinocyte growth factor; EGFR, epidermal growth factor receptor; CNS, central nervous system; MI, myocardial infarction.

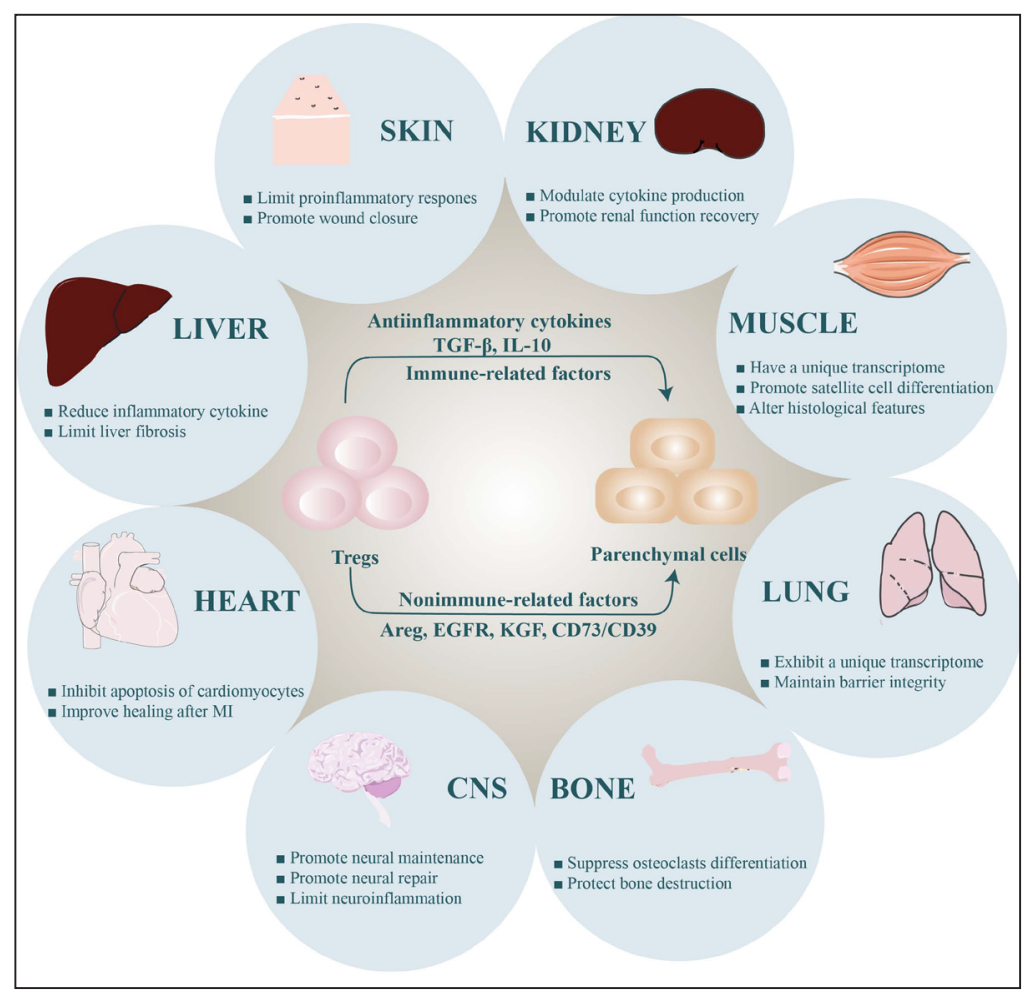

Jin et al. showed that prolonged tissue damage was associated with persistent proinflammatory macrophage accumulation, whereas Treg ablation during this process rescued macrophage homeostasis and skeletal muscle fibre regeneration [26]. Thus, the key to interpreting the role of Tregs in muscle damage is the tissue environment established by the injury signal. Further studies are needed to understand the role of Tregs in muscle repair by integrating signals from injury and local cues.

Other tissue repair functions of Tregs include wound healing and mucosa protection. The skin, lung and intestine are barrier surfaces that are constantly exposed to environmental stimuli and lead to inflammation and tissue damage [27]. Tregs have been implicated in the repair of damaged skin by attenuating IFN- $\gamma$ production and pro-inflammatory macrophage accumulation [28]. Treg-driven wound repair was associated with EGFR expression in Tregs, while specific deletion of EGFR in Tregs resulted in delayed skin wound closure [28]. In lung tissues, Tregs also protect against tissue damage and maintain barrier integrity [29]. For example, Tregs produced amphiregulin for lung tissue protective function following virusinduced inflammation [30]. CCR7 deficiency contributed to Treg homeostasis and trafficking within the lungs, which further modulated wound repair in pulmonary fibrosis [31]. CD73dependent adenosine generation in Tregs also promoted acute lung injury resolution [32]. Tregs limited injury by decreasing allergic airway inflammation and epithelial barrier disruption in house dust mite-derived protease induced-allergic disorders [33]. In addition, Tregs participate in the maintenance of intestinal homeostasis following damage or inflammation or infection [34-36], which has been well reviewed [37].

The influence of Tregs on spinal cord injury provides another example of repair process regulated by Tregs. Treg recruitment to the spinal cord parenchyma occurred at the subacute/chronic phase in the context of a spinal cord injury model, indicating that Tregs participate in the central nervous system (CNS) for neural maintenance and repair [38]. In line with this notion, Tregs were found to recruit protectors of the CNS against autoimmune neuroinflammation [39]. The important Treg-mediated repair tissue that has also been partially addressed is the delineation of bone regeneration in rheumatoid arthritis.

\section{KARGER}


It has been reported that the amount of Foxp $3^{+} \mathrm{T}$ cells was inversely correlated with blood markers of osteoclastogenesis in patients with rheumatoid arthritis and normal controls [40]. Consistently, therapeutic increased Treg numbers improved clinical signs of arthritis and suppressed local and systemic bone destruction in animal models [40]. In vitro, Tregs suppressed osteoclast differentiation, which was essentially dependent on direct cell-cell contact via CTLA-4 [41] and required the cytokines TGF- $\beta$ and IL-4 [42].

Together, these studies suggest that Tregs contribute to diverse repair processes at damaged sites, which is consistent with their anti-inflammatory and tissue repair functions. Beyond the examples given here, the differential repair roles of Tregs in other organs remain unclear.

\section{'Repair' Tregs residing in local tissues}

Treg can be categorized as thymus-derived Tregs (tTregs) and peripherally induced Tregs (pTregs) that develop in peripheral tissues, but specific markers to delineate these two populations are still lacking. The Treg compartment is made of heterogeneous cells of various origins and functions, which is critical for the maintenance of immune-tolerance as well as modulation of nonimmunological processes [7]. Treg subsets exhibit phenotypic and functional diversity in terms of expression of activation or function markers, homing receptors or transcription factors. In the context of tissue injury, although effector-associated markers, such as Foxp3, CTLA4 and IL-10, are still considered essential for the tissue-repair function, Treg subsets and their subphenotypes have been less well characterized. Recently, it has shown that tissue-resident Tregs can exhibit tissue-specific and microenvironmentspecific functions by integrating local cues. Thus, the simplistic prospect of modulating systemic Tregs to improve repair processes will be tempered by new insights into 'repair' Treg in local tissues. In this section, we describe the current knowledge about phenotypic diversity of 'repair' Treg populations in local tissues.

One of the best-characterized examples of 'repair' Tregs is the population found in skeletal muscle. Tregs began to accumulate in the injured muscle after intramuscular administration of cardiotoxin, with their numbers peaking at day 4 and their frequency among $\mathrm{CD} 4^{+} \mathrm{T}$ cells gradually increasing to $\sim 50 \%$ by 14 days and remaining at this frequency for weeks. A similar accumulation pattern of Tregs was also observed in a cryoinjury model and muscular dystrophy, suggesting that site-specific repair mechanisms might exist in the setting of muscle injury. The transcriptome of muscle Tregs was most similar to that of fat Tregs, exhibiting 91\% of the canonical Treg signature. However, the gene expression profile of muscle Treg was distinguishable from those of lymphoid-organ Tregs and Tregs at several inflamed sites. Muscle Tregs also displayed a distinct T cell receptor (TCR), which again suggested that such tissue Tregs may be responding to local signals. Genes encoding the anti-inflammatory cytokine IL-10, chemokine receptor CCR1, cytokine receptor ST2 and growth factors amphiregulin and platelet-derived growth factor were un regulated, whereas genes encoding chemokine receptors (CXCR5 and CCR7) and several proteins implicated in the Wnt signalling pathway (TCF7, LEF1, SATB1) were down regulated in muscle Tregs. Although it has yet to be determined whether these proteins encoding dysregulated genes function in the development and maintenance of muscle Tregs, it should be noted that some of them, such as ST2 and amphiregulin, have been described to play a vital role in Tregmediated repair, which we will discuss later.

Another 'repair' Treg of great interest is lung-Treg that accumulates in the damaged lung during influenza virus infection. The major contributor of repair function is amphiregulinproducing Tregs expressing IL-18R, which are mostly $\mathrm{CD} 44^{\mathrm{hi}} \mathrm{CD} 62 \mathrm{~L}^{\mathrm{lo}}$ and exhibit elevated expression of CD103, PD-1, GITR, CTLA-4 and KLRG1. Microarray-based gene expression profiling revealed that IL-10+IL-18R- 'effector' Tregs and IL-10-IL-18R+ 'repair' Tregs exhibited a similar activation phenotype, with $>90 \%$ of shared differentially expressed genes. The most pronounced overlapping genes were related to Treg suppressive function: Lag3, 
Gzmb, Tnfrsf8, CD30 and CD39. However, analysis of transcripts selectively up regulated in 'repair' Tregs showed that these cells were proficient in extracellular matrix remodelling and tissue repair.

Tregs have also been shown to accumulate in the HCV-infected liver. Intrahepatic Tregs express high levels of HLA-DR, CTLA-4, CD45RO and CCR7, as opposed to their counterparts in peripheral blood, indicating that liver Treg were more differentiated and highly activated [19]. In parallel to the increased expression of functional makers, the ratio of Treg to leukocytes in non-fibrotic livers was higher than those in livers with fibrosis, which suggested that intrahepatic Tregs limit fibrosis in HCV-infected livers [19]. These results were recently extended to show that liver Tregs responding to infection-induced injury showed a high expression of ST2, and ST2 ${ }^{+}$Tregs exhibited elevated expression of CD103, KLRG1, CTLA4 , GITR and PD-1 in mice infected with murine cytomegalovirus [43]. Depending on the infection, liver Tregs produce LAP/TGF $\beta$, GARP and granzyme B [43].

Thus, our present knowledge indicates that repair Tregs exhibit a particular subphenotype compared to their counterparts in peripheral blood, as well as residentsuppressive Tregs tissues. The localization of Tregs in the target tissues seems to be important for repair function. Further research is needed to refine the specialized type of Tregs dedicated to promoting repair in each tissue.

\section{Functional molecules expressed or produced by 'repair' Tregs to mediate the repair process}

The underlying mechanisms by which Tregs contribute to tissue repair focus on two main aspects (Fig. 2). First, Tregs regulate tissue repair in an immune-mediated manner. In the context of tissue injury, Tregs restrict the infiltration of inflammatory cells through secretion of immunosuppressive cytokines, which has been well reviewed elsewhere [9]. For example, Tregs directly induce anti-inflammatory macrophages, which contribute to tissue repair during the initiation, maintenance and resolution phases [12, 44-46]. Tregs produce high levels of IL-10, which act directly on fibroblasts [47]. Tregs decrease CXCL12 expression, which affects fibrocyte recruitment [48]. Tregs suppress neutrophil-driven cytokine release in a CD86-dependent manner [49]. And TGF- $\beta 1$ produced by Tregs promotes their differentiation [50] and enhances formation of tough fibrous tissues at the healing sites [51]. Second, Tregs also make substantial contributions to controlling potentially tissue injury processes in a nonimmunological manner, directly acting on parenchymal cells. For example, Tregs express amphiregulin, a growth factor that plays an important role in healing and regeneration in the intestinal mucosa, lung epithelium and skeletal muscle [52]. Tregs directly interact with osteoblasts and their progenitor, which participate in the bone forming process [53]. Thus, the impact of Tregs on tissue repair and regeneration reflects its traditional (immune) and nontraditional (nonimmune) functions. Here, we discuss the repair factors produced or expressed by 'repair' Tregs, which function on nonimmune targets and coordinate the parenchymal cells to promote tissue repair following injury.

\section{Epidermal growth factor receptor (EGFR)}

The EGFR pathway plays an essential role in normal skin integrity and wound healing through stimulating epidermal and dermal regeneration [54]. Interestingly, EGFR is expressed by Tregs under inflammatory conditions [55]. In vivo, the expression of EGFR was not detected in $\mathrm{CD}^{+}{ }^{+} \mathrm{Foxp}^{+} \mathrm{T}$ cells isolated from skin or draining lymph nodes prior to wounding. After injury, a marked induction of EGFR expression was detected in skin Treg, but not in Tregs from draining lymph nodes [28]. The results suggest that the induction of EGFR occurs preferentially on Tregs in inflamed environments. It has consistently been reported that almost all EGFR ${ }^{+}$Tregs were Foxp3 $3^{\text {High }}$ and CD45RA- (termed activated Tregs); these Tregs gained EGFR expression upon stimulation [55]. Additionally, IL-10 signals that are required for EGFR induction has also been reported. Of note, IL-10-induced EGFR 


\section{Cellular Physiology Cell Physiol Biochem 2017;43:2155-2169 \begin{tabular}{l|l|l} 
DOI: 10.1159/000484295 & $\begin{array}{l}\text { O } 2017 \text { The Author(s). Published by S. Karger AG, Basel } \\
\text { www.karger.com/cpb }\end{array}$
\end{tabular} \\ Zhang et al.: Tregs in Tissue Injury}

Fig. 2. Characteristics of 'repair' Tregs in local tissues and their functions in the repair process. Some tissue-resident Tregs, such as lung, liver and muscleTregs, support tissue repair with distinct properties depending on local tissue microenvironment clues. These 'repair' Tregs exhibit phenotypic and functional diversity in terms of expression of activation or function markers, homing receptors or transcription factors. Areg released by Tregs and KGF, CD39 and CD73 expressed by Tregs directly act on parenchymal cells to contribute to tissue repair and regeneration. In addition, suppressive activity of Tregs promotes phenotypic and functional switching of other immune cells; these immune cells produce pro-repair factors to facilitate tissue repair by promoting proliferation, differentiation and activation

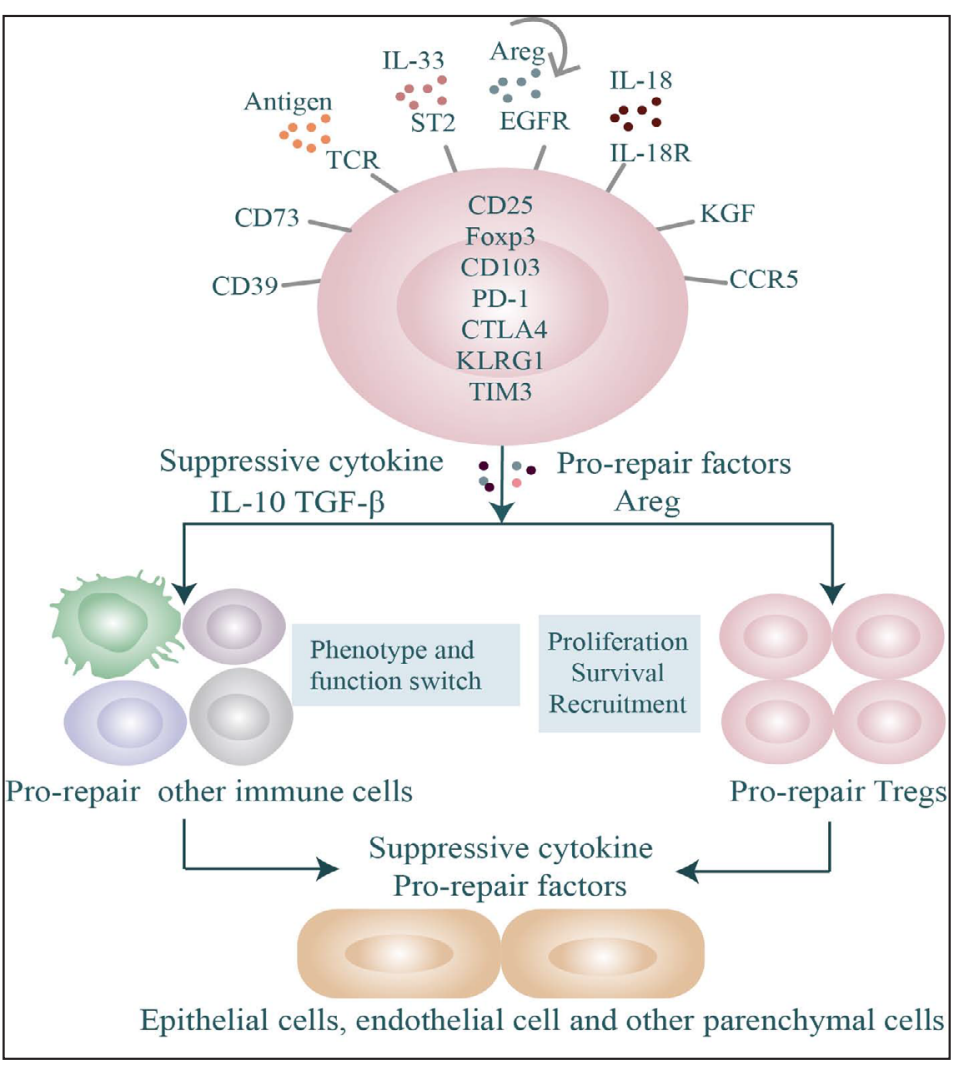
of parenchymal cells. Those effects are further enhanced by several molecules, such as IL-33/ST2, IL18/IL-18R and the EGFR/Areg axis, which have been characterized with regard to their importance for proliferation, survival and recruitment of 'repair' Tregs. Abbreviations are as follows: Areg, amphiregulin; Tregs, regulatory T cells; KGF, keratinocyte growth factor; EGFR, epidermal growth factor receptor.

expression requires activation and recruitment of Src to IL-10 receptor subunit $\alpha$, which increases JAK1/STAT3 signalling activity and results in the expression of EGFR [56].

The EGFR pathway in Tregs also augments their suppressive capacity [55, 57]. Compared with EGFR- Tregs, EGFR ${ }^{+}$Tregs significantly inhibited IFN- $\gamma$, TNF- $\alpha$, perforin and granzyme B production and robustly inhibited CD8 ${ }^{+} \mathrm{T}$ cell proliferation [57]. Similarly, mice with a conditional deletion of EGFR in Tregs have reduced expression of CD25 and CTLA4 [28]. EGFR on Tregs might also enhance Treg survival in inflamed tissues [28]. These data are in line with findings that the deletion of EGFR in Tregs reduced percentages and absolute numbers of Tregs in skin early after wounding, and kinetics of wound closure were significantly delayed [28]. These data suggest that EGFR ${ }^{+}$Tregs with access to inflamed sites promote wound closure in skin; however, EGFR function in Tregs has not been measured in other injured tissues.

\section{Amphiregulin}

Amphiregulin, a ligand of EGFR, has emerged as an important component of Tregmediated tissue repair and regeneration. Both muscle and lung Tregs produce amphiregulin following injury. Pioneering work established that loss of Treg in acutely injured muscle abrogates tissue repair, which could be ameliorated by the administration of recombinant amphiregulin protein. Delving into the mechanism underlying this effect showed that amphiregulin significantly augments the colony-forming efficiency of satellite cells and enhances myogenic differentiation in bulk cultures of satellite cells [58]. However, amphiregulin is widely produced by many epithelial and mesenchymal cell types during 
development and homeostasis, which has been implicated in tissue repair [59, 60]. Exactly how Tregs-derived amphiregulin exhibits a distinct role for tissue repair has only recently emerged. Selective loss of amphiregulin in Tregs did not disrupt the suppressive function in vitro; mice with a Treg-specific amphiregulin deletion showed a normal anti-viral $\mathrm{T}$ cell response, but a rapid decline in lung function was observed [30]. These results account for the direct role for Treg-derived amphiregulin in tissue repair.

The function of amphiregulin on Tregs has also been described in colitis and tumour models. Zaiss et al. reported that mice lacking amphiregulin had insufficient numbers of Tregs to the site of inflammation, which displayed immune regulatory dysfunction [55]. The presence of amphiregulin enhanced the suppressive capacity of Tregs, but had no influence on the overall proliferation or survival of Tregs $[55,57]$. Further evidence to support this result demonstrated that amphiregulin affected posttranslational regulation of Foxp3 expression through EGFR/GSK-3 $\beta$ signalling, which could lead to Foxp3 protein degradation in Tregs [61]. These observations support a positive feedback loop, whereby amphiregulin produced by Tregs promote tissue repair, and autocrine or paracrine amphiregulin signals activate Treg function by the EGFR pathway.

\section{Keratinocyte growth factor}

Recently, keratinocyte growth factor (KGF) has been shown to have crucial roles for Treg mediated lung repair. KGF modulates several mechanisms that are important in alveolar epithelial repair $[62,63]$. For example, KGF increases surfactant protein D, a marker of type II alveolar epithelial cell proliferation, and increases alveolar concentrations of mediators that drive epithelial repair (MMP-9), anti-inflammatory cytokine IL-1R $\alpha$ and GM-CSF [62]. In addition, KGF inhibits apoptosis, maintains sodium channel expression after epithelial injury and promotes migration and wound repair [62].

It has been reported that KGF expression on Tregs can be induced by LPS, which suggests that Tregs have the ability to express KGF under stimulated conditions [64]. Lung Tregs express higher levels of KGF than those from the spleen, which could be stimulated by TCR stimulation, and they failed to further augment expression by addition of IL-18 or IL-33 [65]. In addition, Treg can be regulated by KGF. KGF administration enhanced the number and frequency of Tregs by the selective peripheral expansion of $\mathrm{CD} 4^{+} \mathrm{Foxp} 3^{+}$Tregs and thereafter by enhanced thymic output of newly developed Tregs [66].

Data have demonstrated that transfer of $\mathrm{KGF}^{-}$Tregs failed to augment epithelial proliferation after acute lung injury in Treg-depleted mice [64]. KGF+ Tregs promoted alveolar epithelial proliferation both during the resolution phase in an experimental model of lung injury and during regenerative alveologenesis following pneumonectomy [65]. Type II alveolar epithelial cells (AT2) co-cultured with KGF- Tregs proliferated less than AT2 cells co-cultured with wild-type Tregs [65]. As such, KGF is thought to augment epithelial repair and therefore might improve pulmonary dysfunction in acute respiratory distress syndrome. However, a randomized, placebo-controlled phase 2 trial demonstrated that KGF was not beneficial in the treatment of acute respiratory distress syndrome and might even make clinical outcomes worse [67]. A possible explanation for the low efficacy of KGF in this study is the systemic administration regimen, which cannot directly target the injured lung epithelium. Nevertheless, KGF produced by lung Tregs stands out as potentially important for coordinating repair mechanisms in injured lung tissues. Furthermore, whether $\mathrm{KGF}^{+}$ Tregs are responsible for the difference in repair mechanism that are available in the lung but not in other injured tissues, or whether it reflects shared repair mechanism, is unknown.

CD73/CD39

The ectoenzyme CD39 is an ATP-degrading enzyme that converts both ATP and NAD to AMP, the immediate precursor of adenosine $[68,69]$. CD73 further hydrolyses AMP to adenosine, which subsequently activates the $\mathrm{G}$ protein-coupled adenosine receptor and results in immune-inflammatory effects $[70,71]$. It has been described that CD39/CD73 
expression contributes to their suppressive function following interaction with adenosine receptors expressed on target cells [72]. Furthermore, CD73-expressing exosomes produced by Tregs can also facilitate suppressive function through the production of adenosine. CD73 might promote mesenchymal stromal cell migration, which is essential for their regeneration functions [73].

The role of CD39 on Tregs in limiting tissue injury has been studied in myocardial infarction (MI) [74]. Elevated levels of CD39 can be observed in Treg populations in MI patients after primary percutaneous coronary intervention (PCI). In myocardial ischaemia/ reperfusion injury (MIRI) models, selective depletion of Tregs results in aggravated MIRI, which are suppressed by adoptive transfer of in vitro-activated Tregs. Treg-mediated repair was associated with attenuating cardiomyocyte apoptosis, activating AKT/ERK-mediated pro-survival pathway and inhibiting neutrophil infiltration, which was compromised by CD39 deficiency. Conversely, gain-of-function experiments that genetically deleted CD39 resulted in impairment of Treg-mediated protection against MIRI. These data suggest that CD39 participates in Treg-dependent amelioration of MI. As with CD39, there is evidence that CD73 on T cells can affect cardiac wound healing after MI. In mouse models with CD73 deficiency on T cells, enhanced tissue fibrosis and worse myocardial function were observed after MI, which was associated with accelerated production of pro-inflammatory and profibrotic cytokines (IL-2, INF- $\gamma$, IL-17) [75]. Similarly, genetic deletion of CD73 increased mortality and failure to resolve acute lung injury; however, transfer of wild type Tregs was associated with acute lung injury resolution in Rag/- mice, which was not observed in mice with adoptive transfer of CD73-deficient Tregs [32]. Thus, evidence suggests that CD39/ CD73 is emerging as an important factor to control Treg-mediated repair, particularly in myocardial infarction.

\section{Factors that promote the development and function of 'repair' Tregs in injured tissues}

Several studies are now devoted to identifying the mechanisms through which tissueTregs accumulate in nonlymphoid tissues. However, the cellular and molecular mechanisms underlying the development and function of Tregs that are suitable for injured tissues remain poorly defined. Notably, although there is compelling evidence for heterogeneity among repair Tregs, common factors that regulate 'repair' Treg have been observed. Here, we discuss the emerging understanding of novel factors that guide development, accumulation and differentiation of Tregs in the context of injury microenvironment cues.

\section{IL-33/ST2 signals}

A common factor in the mechanism that mediates repair Treg accumulation and function in injured tissues is IL-33/ST2. IL-33, a member of the IL-1 family of cytokines, is normally released by damaged or necrotic barrier cells (endothelial and epithelial cells); ST2, also known as IL-1RL1, is expressed by many immune cells [76, 77]. Several current works have generated interest in their roles in the activation and expansion of Treg populations, particularly linking IL33/ST2 to controlling Tregs homeostasis in the nonlymphoid tissues $[23,78]$. IL-33/ST2 drives positive feedback loops in Treg activation: IL-33 either directly or indirectly enhances expression and function of the transcription factors Foxp3, GATA3 and STAT5, which in turn promote the expression of ST2 in Tregs [79].

In the context of injury, the contribution of IL-33 and its receptor ST2 to lung, muscle and liver Treg accumulation following injury has already been highlighted. In muscle tissue, IL-33 is produced mainly by fibro/adipogenic progenitors (FAPs). FAPs can engender both fibroblasts and adipocytes, which have been assigned a substantial role in the regeneration of myofibres within aged skeletal muscle $[80,81]$. ST2 is constitutively expressed on muscle Tregs, mice specifically ablated ST2 in Tregs showed impaired Treg accumulation in injured muscle. Muscle-Tregs were expanded by IL-33, which exhibited a typical muscle Treg profile 
after injury, but IL-33 did not enhance the recruitment of circulating Tregs to the muscle. These results suggest that the IL-33 effect in muscle injury seems to primarily be local.

As mentioned above, liver Tregs constitutively express high levels of ST2, and ST2+ Treg exhibit a high proliferative capacity [43], which has also been observed in lung Tregs [30]. Unlike muscle tissues, IL-33 is mainly produced by endothelial cells in the livers of uninfected mice and is produced by macrophages in infected livers [43]. The function of IL33/ST2 signals on liver Tregs was demonstrated by the finding that the accumulation of Treg was impaired in the livers of ST2 $\%$ mice during the peak of the Treg response [43]. In line with this data, liver pathology of ST2\% mice was characterized by hepatocellular necrosis, mononuclear infiltrates and extravasation of erythrocytes [43]. Consistently, IL-33/ST2 has been reported to suppress the activation of caspase 3 and prevent concanavalin A-induced liver injury [82].

Collectively, these data indicate that IL-33/ST2 signals control the expansion and function of repair Tregs in the target lung, liver and muscle tissues. The factors that determine why repair Tregs in local tissues express higher levels of ST2 compared with their counterparts in other sites remain unclear, and the factors that control ST2 expression in the context of injury are still unknown.

\section{TCR signals}

TCR signals play a crucial role in regulating Treg differentiation, homeostasis and function [83]. Recent studies have demonstrated that TCR sequences of tissue-Tregs have little overlap with Tregs found in lymphoid tissues. In lung and muscle tissues, repair Tregs display a distinct, clonally expanded TCR repertoire, which also shows signs of antigenic selection for repair Tregs following injury. In line with a crucial role of TCR-controlled suppressive function in Treg, TCR stimulation in the presence of IL-2 induces proliferation and production of IL-10; in the absence of TCR, IL-10 levels are below the limit of detection [30]. Evidence for TCR in recruiting Tregs to the site of injury was provided by the fact that the small subset of amphiregulin ${ }^{+}$Treg in spleen shared TCR sequences with amphiregulin ${ }^{+}$ or amphiregulin- Treg in muscle [30].

Notably, TCR signals are not required for amphiregulin production in repair Tregs. Reports have shown that TCR stimulation fails to induce amphiregulin production on a per cell basis and also led to a reduction in cell-associated amphiregulin levels [30]. A similar effect was observed in vivo, demonstrating that amphiregulin is efficiently produced by ex vivo-isolated TCR-deficient Tregs after influenza virus infection [30]. Thus, these data suggest that alternative mechanisms likely operate to regulate amphiregulin production in repair Tregs, although TCR signals can effectively elicit suppressor functions.

\section{Other factors}

Other factors have been associated with the development and function of Tregs in the repair process. For example, IL-18 has an important role in the generation of Tregs [84]. Studies have suggested that IL-18/IL-18R signals also influence the repair function of Treg. Repair Treg in the injured lung coexpress high levels of IL-18R; consistently, IL-18 is highly produced in bronchoalveolar lavage fluid after infection [30]. IL-18 leads to increased amphiregulin production by Treg independent of TCR engagement [30]. It has also been demonstrated that CCR5 is responsible for the accumulation of Tregs in damaged sites. CCR5 promotes recruitment of Tregs in infarcted myocardium, and its deficiency has been shown to deteriorate matrix degradation and cardiac remodelling [85]. In addition, research on tissue-Tregs has recently found that TGF- $\beta$ in Tregs is an upstream factor controlling Treg activity in specific tissue environments [86]. The discovery of new tissue-specific regulation of Treg functions might contribute to uncovering molecular mechanisms underlying Tregmediated repair in local tissues. 


\section{Conclusion}

The identification of distinct populations of Tregs and the subsequent recognition of mechanisms that drive those Tregs to exhibit tissue repair activity have provided new insights into how Tregs respond through nonimmune-mediated mechanisms. Despite advances in the field studying the crosstalk between Tregs and tissue repair, many questions have not yet been addressed.

Similar to the detailed characterization of macrophages in tissue repair, a thorough and careful mapping of Tregs in different tissues is needed, including surface markers and transcriptional and epigenetic profiles $[87,88]$. The importance here is to sort out tissuespecific repair factors, such as amphiregulin for muscle, which are unknown for many tissues. A limitation of most repair Treg-related studies has been the inability to discriminate tissueresident Tregs and natural or induced Tregs, which are recruited to injured tissues. Therefore, it remains unknown where repair-associated Tregs come from, how they develop and when they recruit and differentiate to sites of tissue injury. The issues of Treg lineage stability and phenotypic plasticity have added an additional layer of complexity [89]. Addressing these issues undoubtedly will be of use in understanding the complexity of Tregs in maintaining tissue homeostasis.

Functionally, how Tregs influence regulatory networks in local tissue damage remains unclear, which should be integrated with site-specific repair mechanisms. It also remains unknown which other immune cells and supportive tissue cells might contact these cells and which mechanisms are involved. Thus, the issue is not whether Tregs are central to tissue repair but how Treg exert regulatory effects within different local microenvironments. For example, there is a tightly regulated immune cell network encompassing Tregs and macrophages that promotes repair by a cytokine-mediated pathway [46, 90]. A better understanding of the intimate relationship among Tregs, other immune cells and relevant tissue cells will provide clues to the pathology involved in tissue damage and repair.

In addition, it is unclear how Tregs finely tune anti-inflammatory and pro-inflammatory responses and how they terminate over-repair, which signals control in this process. It is also important to explore how Tregs function once injurious trigger is eliminated. This issue is of interest because aberrant repair can contribute to persistent injury and pathological fibrosis $[91,92]$. The activity of Tregs needs to strike the balance between restraining deleterious inflammatory and exuberant fibrosis and facilitating regenerative responses.

Despite all this, several approaches targeting Tregs have been used to promote repair in animal injury models. Indeed, the efficacy of adoptive transfer of Tregs has been observed in repairing the infarcted heart [93]. Strategies that expand Tregs by receptors on Tregs also hold great promise. For example, IL-2 was described to attenuate adverse remodelling after myocardial infarction by specifically expanding Tregs [94]. In fact, the ability of IL-2 to activate Tregs has proved beneficial in the treatment of autoimmune and inflammatory diseases [95]. Although pro-repair capacities of Tregs has not been brought to the clinic, the ultimate goal of understanding how Tregs function in injury drives the development of repair mechanisms and provides a novel therapeutic strategy that can enhance recovery in patients with tissue injury.

\section{Acknowledgements}

This work was supported by grants from the National Natural Science Foundation of China (Grant No.81603122).

\section{Disclosure Statement}

The authors declare there are no conflicts of interest.

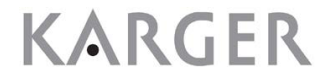




\section{Cellular Physiology Cell Physiol Biochem 2017;43:2155-2169

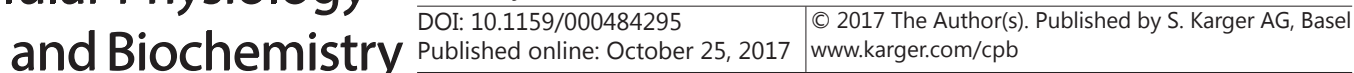 \\ Zhang et al.: Tregs in Tissue Injury}

\section{References}

1 Chazaud B: Macrophages: supportive cells for tissue repair and regeneration. Immunobiology 2014;219:172-178.

2 Forbes SJ, Rosenthal N: Preparing the ground for tissue regeneration: from mechanism to therapy. Nat Med 2014;20:857-869.

- Bouchery T, Harris NL: Specific repair by discerning macrophages. Science 2017;356:1014.

4 Minutti CM, Jackson-Jones LH, Garcia-Fojeda B, Knipper JA, Sutherland TE, Logan N, Rinqvist E, GuillamatPrats R, Ferenbach DA, Artigas A, Stamme C, Chroneos ZC, Zaiss DM, Casals C, Allen JE: Local amplifiers of IL-4Ralpha-mediated macrophage activation promote repair in lung and liver. Science 2017;356:10761080.

5 Bosurgi L, Cao YG, Cabeza-Cabrerizo M, Tucci A, Hughes LD, Kong Y, Weinstein JS, Licona-Limon P, Schmid ET, Pelorosso F, Gagliani N, Craft JE, Flavell RA, Ghosh S, Rothlin CV: Macrophage function in tissue repair and remodeling requires IL-4 or IL-13 with apoptotic cells. Science 2017;356:1072-1076.

6 Kanamori M, Nakatsukasa H, Okada M, Lu Q Yoshimura A: Induced Regulatory T Cells: Their Development, Stability, and Applications. Trends Immunol 2016;37:803-811.

7 Burzyn D, Benoist C, Mathis D: Regulatory T cells in nonlymphoid tissues. Nat Immunol 2013;14:10071013.

-8 Liston A, Gray DH: Homeostatic control of regulatory T cell diversity. Nat Rev Immunol 2014;14:154-165.

-9 Lei H, Schmidt-Bleek K, Dienelt A, Reinke P, Volk HD: Regulatory T cell-mediated anti-inflammatory effects promote successful tissue repair in both indirect and direct manners. Front Pharmacol 2015;6:184.

10 Panduro M, Benoist C, Mathis D: Tissue Tregs. Annu Rev Immunol 2016;34:609-633.

11 Tang TT, Yuan J, Zhu ZF, Zhang WC, Xiao H, Xia N, Yan XX, Nie SF, Liu J, Zhou SF, Li JJ, Yao R, Liao MY, Tu X, Liao YH, Cheng X: Regulatory T cells ameliorate cardiac remodeling after myocardial infarction. Basic Res Cardiol 2012;107:232.

-12 Weirather J, Hofmann UD, Beyersdorf N, Ramos GC, Vogel B, Frey A, Ertl G, Kerkau T, Frantz S: Foxp3+ CD4+ $\mathrm{T}$ cells improve healing after myocardial infarction by modulating monocyte/macrophage differentiation. Circ Res 2014;115:55-67.

13 Saxena A, Dobaczewski M, Rai V, Haque Z, Chen W, Li N, Frangogiannis NG: Regulatory T cells are recruited in the infarcted mouse myocardium and may modulate fibroblast phenotype and function. Am J Physiol Heart Circ Physiol 2014;307:H1233-1242.

14 Gandolfo MT, Jang HR, Bagnasco SM, Ko GJ, Agreda P, Satpute SR, Crow MT, King LS, Rabb H: Foxp3+ regulatory T cells participate in repair of ischemic acute kidney injury. Kidney Int 2009;76:717-729.

15 Kinsey GR, Sharma R, Huang L, Li L, Vergis AL, Ye H, Ju ST, Okusa MD: Regulatory T cells suppress innate immunity in kidney ischemia-reperfusion injury. J Am Soc Nephrol 2009;20:1744-1753.

16 Jun C, Ke W, Qingshu L, Ping L, Jun D, Jie L, Bo C, Su M: Protective effect of CD4(+)CD25(high)CD127(low) regulatory $\mathrm{T}$ cells in renal ischemia-reperfusion injury. Cell Immunol 2014;289:106-111.

-17 Jun C, Qingshu L, Ke W, Ping L, Jun D, Jie L, Su M: Protective Effect of CXCR3(+)CD4(+)CD25(+)Foxp3(+) Regulatory T Cells in Renal Ischemia-Reperfusion Injury. Mediators Inflamm 2015;2015:360973.

18 Katz SC, Ryan K, Ahmed N, Plitas G, Chaudhry UI, Kingham TP, Naheed S, Nguyen C, Somasundar P, Espat NJ, Junghans RP, Dematteo RP: Obstructive jaundice expands intrahepatic regulatory T cells, which impair liver T lymphocyte function but modulate liver cholestasis and fibrosis. J Immunol 2011;187:1150-1156.

$\checkmark 19$ Claassen MA, de Knegt RJ, Tilanus HW, Janssen HL, Boonstra A: Abundant numbers of regulatory T cells localize to the liver of chronic hepatitis $\mathrm{C}$ infected patients and limit the extent of fibrosis. J Hepatol 2010;52:315-321.

20 Langhans B, Kramer B, Louis M, Nischalke HD, Huneburg R, Staratschek-Jox A, Odenthal M, Manekeller S, Schepke M, Kalff J, Fischer HP, Schultze JL, Spengler U: Intrahepatic IL-8 producing Foxp3(+)CD4(+) regulatory T cells and fibrogenesis in chronic hepatitis C. J Hepatol 2013;59:229-235.

21 Burzyn D, Kuswanto W, Kolodin D, Shadrach JL, Cerletti M, Jang Y, Sefik E, Tan TG, Wagers AJ, Benoist C, Mathis D: A special population of regulatory T cells potentiates muscle repair. Cell 2013;155:1282-1295.

22 Castiglioni A, Corna G, Rigamonti E, Basso V, Vezzoli M, Monno A, Almada AE, Mondino A, Wagers AJ, Manfredi AA, Rovere-Querini P: FOXP3+ T Cells Recruited to Sites of Sterile Skeletal Muscle Injury Regulate the Fate of Satellite Cells and Guide Effective Tissue Regeneration. PLoS One 2015;10:e0128094. 


\section{Cellular Physiology Cell Physiol Biochem 2017;43:2155-2169 \begin{tabular}{l|l|l} 
and Biochemistry $10.1159 / 000484295$ & $\begin{array}{l}\text { C) } 2017 \text { The Author(s). Published by S. Karger AG, Basel } \\
\text { www.karger.com/cpb }\end{array}$
\end{tabular} \\ Zhang et al.: Tregs in Tissue Injury}

23 Kuswanto W, Burzyn D, Panduro M, Wang KK, Jang YC, Wagers AJ, Benoist C, Mathis D: Poor Repair of Skeletal Muscle in Aging Mice Reflects a Defect in Local, Interleukin-33-Dependent Accumulation of Regulatory T Cells. Immunity 2016;44:355-367.

-24 Jang YC, Sinha M, Cerletti M, Dall'Osso C, Wagers AJ: Skeletal muscle stem cells: effects of aging and metabolism on muscle regenerative function. Cold Spring Harb Symp Quant Biol 2011;76:101-111.

-25 Villalta SA, Rosenthal W, Martinez L, Kaur A, Sparwasser T, Tidball JG, Margeta M, Spencer MJ, Bluestone JA: Regulatory T cells suppress muscle inflammation and injury in muscular dystrophy. Sci Transl Med 2014;6:258ra142.

-26 Jin RM, Blair SJ, Warunek J, Heffner RR, Blader IJ, Wohlfert EA: Regulatory T Cells Promote Myositis and Muscle Damage in Toxoplasma gondii Infection. J Immunol 2017;198:352-362.

27 Monticelli LA, Osborne LC, Noti M, Tran SV, Zaiss DM, Artis D: IL-33 promotes an innate immune pathway of intestinal tissue protection dependent on amphiregulin-EGFR interactions. Proc Natl Acad Sci U S A 2015;112:10762-10767.

28 Nosbaum A, Prevel N, Truong HA, Mehta P, Ettinger M, Scharschmidt TC, Ali NH, Pauli ML, Abbas AK, Rosenblum MD: Cutting Edge: Regulatory T Cells Facilitate Cutaneous Wound Healing. J Immunol 2016;196:2010-2014.

29 Ding J, Su J, Zhang L, Ma J: Crocetin Activates Foxp3 Through TIPE2 in Asthma-Associated Treg Cells. Cell Physiol Biochem 2015;37:2425-2433.

30 Arpaia N, Green JA, Moltedo B, Arvey A, Hemmers S, Yuan S, Treuting PM, Rudensky AY: A Distinct Function of Regulatory T Cells in Tissue Protection. Cell 2015;162:1078-1089.

-31 Trujillo G, Hartigan AJ, Hogaboam CM: T regulatory cells and attenuated bleomycin-induced fibrosis in lungs of CCR7-/- mice. Fibrogenesis Tissue Repair 2010;3:18.

-32 Ehrentraut H, Clambey ET, McNamee EN, Brodsky KS, Ehrentraut SF, Poth JM, Riegel AK, Westrich JA, Colgan SP, Eltzschig HK: CD73+ regulatory T cells contribute to adenosine-mediated resolution of acute lung injury. FASEB J 2013;27:2207-2219.

-33 Morita H, Arae K, Unno H, Miyauchi K, Toyama S, Nambu A, Oboki K, Ohno T, Motomura K, Matsuda A, Yamaguchi S, Narushima S, Kajiwara N, Iikura M, Suto H, McKenzie AN, Takahashi T, Karasuyama H, Okumura K, Azuma M, Moro K, Akdis CA, Galli SJ, Koyasu S, Kubo M, Sudo K, Saito H, Matsumoto K, Nakae S: An Interleukin-33-Mast Cell-Interleukin-2 Axis Suppresses Papain-Induced Allergic Inflammation by Promoting Regulatory T Cell Numbers. Immunity 2015;43:175-186.

34 Maloy KJ, Salaun L, Cahill R, Dougan G, Saunders NJ, Powrie F: CD4+CD25+ T(R) cells suppress innate immune pathology through cytokine-dependent mechanisms. J Exp Med 2003;197:111-119.

35 Kim SV, Xiang WV, Kwak C, Yang Y, Lin XW, Ota M, Sarpel U, Rifkin DB, Xu R, Littman DR: GPR15-mediated homing controls immune homeostasis in the large intestine mucosa. Science 2013;340:1456-1459.

-36 Yang X, Bai H, Wang Y, Li J, Zhou Q, Cai W, Han J, Zhu X, Dong M, Hu D: Deletion of regulatory T cells supports the development of intestinal ischemia-reperfusion injuries. J Surg Res 2013;184:832-837.

37 Tanoue T, Atarashi K, Honda K: Development and maintenance of intestinal regulatory T cells. Nat Rev Immunol 2016;16:295-309.

-38 Kipnis J, Schwartz M: Controlled autoimmunity in CNS maintenance and repair: naturally occurring CD4+CD25+ regulatory T-Cells at the crossroads of health and disease. Neuromolecular Med 2005;7:197206.

-39 Jones A, Hawiger D: Peripherally Induced Regulatory T Cells: Recruited Protectors of the Central Nervous System against Autoimmune Neuroinflammation. Front Immunol 2017;8:532.

-40 Zaiss MM, Frey B, Hess A, Zwerina J, Luther J, Nimmerjahn F, Engelke K, Kollias G, Hunig T, Schett G, David JP: Regulatory T cells protect from local and systemic bone destruction in arthritis. J Immunol 2010;184:7238-7246.

41 Zaiss MM, Axmann R, Zwerina J, Polzer K, Guckel E, Skapenko A, Schulze-Koops H, Horwood N, Cope A, Schett G: Treg cells suppress osteoclast formation: a new link between the immune system and bone. Arthritis Rheum 2007;56:4104-4112.

42 Kim YG, Lee CK, Nah SS, Mun SH, Yoo B, Moon HB: Human CD4+CD25+ regulatory T cells inhibit the differentiation of osteoclasts from peripheral blood mononuclear cells. Biochem Biophys Res Commun 2007;357:1046-1052. 


\section{Cellular Physiology Cell Physiol Biochem 2017;43:2155-2169

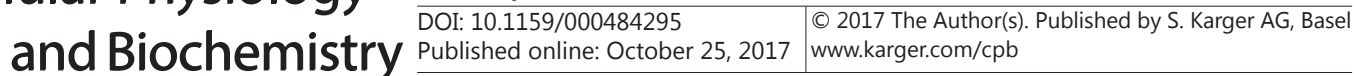 \\ Zhang et al.: Tregs in Tissue Injury}

43 Popovic B, Golemac M, Podlech J, Zeleznjak J, Bilic-Zulle L, Lukic ML, Cicin-Sain L, Reddehase MJ, Sparwasser T, Krmpotic A, Jonjic S: IL-33/ST2 pathway drives regulatory T cell dependent suppression of liver damage upon cytomegalovirus infection. PLoS Pathog 2017;13:e1006345.

$\$ 44$ Abelius MS, Ernerudh J, Berg G, Matthiesen L, Nilsson LJ, Jenmalm MC: High cord blood levels of the T-helper 2-associated chemokines CCL17 and CCL22 precede allergy development during the first 6 years of life. Pediatr Res 2011;70:495-500.

45 Telithromycin: review of adverse effects. Prescrire Int 2014;23:264-266.

46 Wynn TA, Vannella KM: Macrophages in Tissue Repair, Regeneration, and Fibrosis. Immunity 2016;44:450462.

-47 Kuroiwa K, Li H, Tago K, Iwahana H, Yanagisawa K, Komatsu N, Oshikawa K, Sugiyama Y, Arai T, Tominaga SI: Construction of ELISA system to quantify human ST2 protein in sera of patients. Hybridoma 2000;19:151-159.

-48 Garibaldi BT, D’Alessio FR, Mock JR, Files DC, Chau E, Eto Y, Drummond MB, Aggarwal NR, Sidhaye V, King LS: Regulatory T cells reduce acute lung injury fibroproliferation by decreasing fibrocyte recruitment. Am J Respir Cell Mol Biol 2013;48:35-43.

-49 Chen L, Fan J, Li Y, Shi X, Ju D, Yan Q Yan X, Han L, Zhu H: Modified Jiu Wei Qiang Huo decoction improves dysfunctional metabolomics in influenza A pneumonia-infected mice. Biomed Chromatogr 2014;28:468474.

-50 Shen Y, Wei Y, Wang Z, Jing Y, He H, Yuan J, Li R, Zhao Q Wei L, Yang T, Lu J: TGF-beta regulates hepatocellular carcinoma progression by inducing Treg cell polarization. Cell Physiol Biochem 2015;35:1623-1632.

-51 Arimura H, Shukunami C, Tokunaga T, Karasugi T, Okamoto N, Taniwaki T, Sakamoto H, Mizuta H, Hiraki Y: TGF-beta1 Improves Biomechanical Strength by Extracellular Matrix Accumulation Without Increasing the Number of Tenogenic Lineage Cells in a Rat Rotator Cuff Repair Model. Am J Sports Med 2017;45:23942404.

52 Andrikopoulos G, Tzeis S, Terentes-Printzios D, Varounis C, Vlachopoulos C, Mantas I, Patsilinakos S, Lampropoulos S, Olympios C, Kartalis A, Manolis A, Gotsis A, Triposkiadis F, Tsaknakis T, Goudevenos I, Kaprinis I, Pras A, Vasiliou F, Skoumpourdis E, Sakka G, Draganigos A, Vardas P: Impact of income status on prognosis of acute coronary syndrome patients during Greek financial crisis. Clin Res Cardiol 2016;105:518-526.

53 Ge CJ, Lu SZ, Liu H: [Effects of Maixuekang Capsule on the platelet aggregation rate and its long-term prognosis of patients with acute coronary syndrome under percutaneous coronary intervention]. Zhongguo Zhong Xi Yi Jie He Za Zhi 2012;32:906-909.

54 Bodnar RJ: Epidermal Growth Factor and Epidermal Growth Factor Receptor: The Yin and Yang in the Treatment of Cutaneous Wounds and Cancer. Adv Wound Care (New Rochelle) 2013;2:24-29.

-55 Zaiss DM, van Loosdregt J, Gorlani A, Bekker CP, Grone A, Sibilia M, van Bergen en Henegouwen PM, Roovers RC, Coffer PJ, Sijts AJ: Amphiregulin enhances regulatory T cell-suppressive function via the epidermal growth factor receptor. Immunity 2013;38:275-284.

56 Hsu TI, Wang YC, Hung CY, Yu CH, Su WC, Chang WC, Hung JJ: Positive feedback regulation between IL10 and EGFR promotes lung cancer formation. Oncotarget 2016;7:20840-20854.

57 Dai K, Huang L, Chen J, Yang L, Gong Z: Amphiregulin promotes the immunosuppressive activity of intrahepatic CD4+ regulatory T cells to impair CD8+ T-cell immunity against hepatitis B virus infection. Immunology 2015;144:506-517.

-58 Tidball JG: Regulation of muscle growth and regeneration by the immune system. Nat Rev Immunol 2017;17:165-178.

-59 Meulenbroeks C, van Weelden H, Schwartz C, Voehringer D, Redegeld FA, Rutten VP, Willemse T, Sijts AJ, Zaiss DM: Basophil-derived amphiregulin is essential for UVB irradiation-induced immune suppression. J Invest Dermatol 2015;135:222-228.

60 Monticelli LA, Sonnenberg GF, Abt MC, Alenghat T, Ziegler CG, Doering TA, Angelosanto JM, Laidlaw BJ, Yang CY, Sathaliyawala T, Kubota M, Turner D, Diamond JM, Goldrath AW, Farber DL, Collman RG, Wherry EJ, Artis D: Innate lymphoid cells promote lung-tissue homeostasis after infection with influenza virus. Nat Immunol 2011;12:1045-1054.

61 Wang S, Zhang Y, Wang Y, Ye P, Li J, Li H, Ding Q, Xia J: Amphiregulin Confers Regulatory T Cell Suppressive Function and Tumor Invasion via the EGFR/GSK-3beta/Foxp3 Axis. J Biol Chem 2016;291:21085-21095. 


\section{Cellular Physiology Cell Physiol Biochem 2017;43:2155-2169 and Biochemistry Published online: OCtober 25, $2017 \mid \begin{aligned} & \text { OO 2017 The Author(s). Published by S. Karger AG, Basel } \\ & \text { www.karger.com/cpb }\end{aligned}$ \\ Zhang et al.: Tregs in Tissue Injury}

-62 Shyamsundar M, McAuley DF, Ingram RJ, Gibson DS, O’Kane D, McKeown ST, Edwards A, Taggart C, Elborn JS, Calfee CS, Matthay MA, O’Kane CM: Keratinocyte growth factor promotes epithelial survival and resolution in a human model of lung injury. Am J Respir Crit Care Med 2014;189:1520-1529.

63 Ware LB, Matthay MA: Keratinocyte and hepatocyte growth factors in the lung: roles in lung development, inflammation, and repair. Am J Physiol Lung Cell Mol Physiol 2002;282:L924-940.

64 Dial CF, Tune MK, Doerschuk CM, Mock JR: Foxp3+ Regulatory T Cell Expression of Keratinocyte Growth Factor Enhances Lung Epithelial Proliferation. Am J Respir Cell Mol Biol 2017;57:162-173.

65 Dial CF, Tune MK, Doerschuk CM, Mock JR: Foxp3+ Regulatory T Cell Expression of Keratinocyte Growth Factor Enhances Lung Epithelial Proliferation. Am J Respir Cell Mol Biol 2017;57:162-173.

66 Bruinsma M, van Soest PL, Leenen PJ, Lambrecht BN, Cupedo T, Lowenberg B, Cornelissen JJ, Braakman E: Keratinocyte growth factor induces expansion of murine peripheral CD4+Foxp3+ regulatory $\mathrm{T}$ cells and increases their thymic output. J Immunol 2007;179:7424-7430.

67 McAuley DF, Cross LM, Hamid U, Gardner E, Elborn JS, Cullen KM, Dushianthan A, Grocott MP, Matthay MA, O'Kane CM: Keratinocyte growth factor for the treatment of the acute respiratory distress syndrome (KARE): a randomised, double-blind, placebo-controlled phase 2 trial. Lancet Respir Med 2017;5:484-491.

68 Eltzschig HK, Sitkovsky MV, Robson SC: Purinergic signaling during inflammation. N Engl J Med 2012;367:2322-2333.

69 Zimmermann H, Zebisch M, Strater N: Cellular function and molecular structure of ecto-nucleotidases. Purinergic Signal 2012;8:437-502.

-70 Hasko G, Linden J, Cronstein B, Pacher P: Adenosine receptors: therapeutic aspects for inflammatory and immune diseases. Nat Rev Drug Discov 2008;7:759-770.

-71 Feoktistov I, Biaggioni I: Role of adenosine A(2B) receptors in inflammation. Adv Pharmacol 2011;61:115144.

72 Deaglio S, Dwyer KM, Gao W, Friedman D, Usheva A, Erat A, Chen JF, Enjyoji K, Linden J, Oukka M, Kuchroo VK, Strom TB, Robson SC: Adenosine generation catalyzed by CD39 and CD73 expressed on regulatory T cells mediates immune suppression. J Exp Med 2007;204:1257-1265.

73 Ode A, Kopf J, Kurtz A, Schmidt-Bleek K, Schrade P, Kolar P, Buttgereit F, Lehmann K, Hutmacher DW, Duda GN, Kasper G: CD73 and CD29 concurrently mediate the mechanically induced decrease of migratory capacity of mesenchymal stromal cells. Eur Cell Mater 2011;22:26-42.

-74 Xia N, Jiao J, Tang TT, Lv BJ, Lu YZ, Wang KJ, Zhu ZF, Mao XB, Nie SF, Wang Q, Tu X, Xiao H, Liao YH, Shi GP, Cheng X: Activated regulatory T-cells attenuate myocardial ischaemia/reperfusion injury through a CD39dependent mechanism. Clin Sci (Lond) 2015;128:679-693.

-75 Borg N, Alter C, Gorldt N, Jacoby C, Ding Z, Steckel B, Quast C, Bonner F, Friebe D, Temme S, Flogel U, Schrader J: CD73 on T-Cells Orchestrates Cardiac Wound Healing After Myocardial Infarction by Purinergic Metabolic Reprogramming. Circulation 2017;136:297-313.

-76 Liew FY, Girard JP, Turnquist HR: Interleukin-33 in health and disease. Nat Rev Immunol 2016;16:676-689.

77 Martin NT, Martin MU: Interleukin 33 is a guardian of barriers and a local alarmin. Nat Immunol 2016;17:122-131.

-78 Schiering C, Krausgruber T, Chomka A, Frohlich A, Adelmann K, Wohlfert EA, Pott J, Griseri T, Bollrath J, Hegazy AN, Harrison OJ, Owens BM, Lohning M, Belkaid Y, Fallon PG, Powrie F: The alarmin IL-33 promotes regulatory T-cell function in the intestine. Nature 2014;513:564-568.

79 Peine M, Marek RM, Lohning M: IL-33 in T Cell Differentiation, Function, and Immune Homeostasis. Trends Immunol 2016;37:321-333.

80 Joe AW, Yi L, Natarajan A, Le Grand F, So L, Wang J, Rudnicki MA, Rossi FM: Muscle injury activates resident fibro/adipogenic progenitors that facilitate myogenesis. Nat Cell Biol 2010;12:153-163.

-81 Uezumi A, Fukada S, Yamamoto N, Takeda S, Tsuchida K: Mesenchymal progenitors distinct from satellite cells contribute to ectopic fat cell formation in skeletal muscle. Nat Cell Biol 2010;12:143-152.

82 Volarevic V, Mitrovic M, Milovanovic M, Zelen I, Nikolic I, Mitrovic S, Pejnovic N, Arsenijevic N, Lukic ML: Protective role of IL-33/ST2 axis in Con A-induced hepatitis. J Hepatol 2012;56:26-33.

-83 Li MO, Rudensky AY: T cell receptor signalling in the control of regulatory T cell differentiation and function. Nat Rev Immunol 2016;16:220-233.

-84 Oertli M, Sundquist M, Hitzler I, Engler DB, Arnold IC, Reuter S, Maxeiner J, Hansson M, Taube C, QuidingJarbrink M, Muller A: DC-derived IL-18 drives Treg differentiation, murine Helicobacter pylori-specific immune tolerance, and asthma protection. J Clin Invest 2012;122:1082-1096. 


\section{Cellular Physiology Cell Physiol Biochem 2017;43:2155-2169

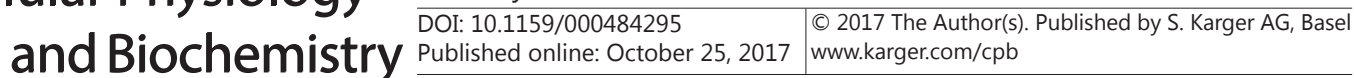 \\ Zhang et al.: Tregs in Tissue Injury}

85 Dobaczewski M, Xia Y, Bujak M, Gonzalez-Quesada C, Frangogiannis NG: CCR5 signaling suppresses inflammation and reduces adverse remodeling of the infarcted heart, mediating recruitment of regulatory T cells. Am J Pathol 2010;176:2177-2187.

86 Konkel JE, Zhang D, Zanvit P, Chia C, Zangarle-Murray T, Jin W, Wang S, Chen W: Transforming Growth Factor-beta Signaling in Regulatory T Cells Controls T Helper-17 Cells and Tissue-Specific Immune Responses. Immunity 2017;46:660-674.

-87 Murray PJ, Allen JE, Biswas SK, Fisher EA, Gilroy DW, Goerdt S, Gordon S, Hamilton JA, Ivashkiv LB, Lawrence T, Locati M, Mantovani A, Martinez FO, Mege JL, Mosser DM, Natoli G, Saeij JP, Schultze JL, Shirey KA, Sica A, Suttles J, Udalova I, van Ginderachter JA, Vogel SN, Wynn TA: Macrophage activation and polarization: nomenclature and experimental guidelines. Immunity 2014;41:14-20.

-88 Davies LC, Jenkins SJ, Allen JE, Taylor PR: Tissue-resident macrophages. Nat Immunol 2013;14:986-995.

89 Hori S: Lineage stability and phenotypic plasticity of Foxp3(+) regulatory T cells. Immunol Rev 2014;259:159-172.

90 Laurent P, Jolivel V, Manicki P, Chiu L, Contin-Bordes C, Truchetet ME, Pradeu T: Immune-Mediated Repair: A Matter of Plasticity. Front Immunol 2017;8:454.

91 Pellicoro A, Ramachandran P, Iredale JP, Fallowfield JA: Liver fibrosis and repair: immune regulation of wound healing in a solid organ. Nat Rev Immunol 2014;14:181-194.

-92 Anders HJ: Immune system modulation of kidney regeneration--mechanisms and implications. Nat Rev Nephrol 2014;10:347-358.

-93 Sharir R, Semo J, Shimoni S, Ben-Mordechai T, Landa-Rouben N, Maysel-Auslender S, Shaish A, Entin-Meer M, Keren G, George J: Experimental myocardial infarction induces altered regulatory T cell hemostasis, and adoptive transfer attenuates subsequent remodeling. PLoS One 2014;9:e113653.

$\$ 94$ Zeng Z, Yu K, Chen L, Li W, Xiao H, Huang Z: Interleukin-2/Anti-Interleukin-2 Immune Complex Attenuates Cardiac Remodeling after Myocardial Infarction through Expansion of Regulatory T Cells. J Immunol Res 2016;2016:8493767.

95 Boyman 0, Sprent J: The role of interleukin-2 during homeostasis and activation of the immune system. Nat Rev Immunol 2012;12:180-190. 